\title{
Development Proposals in China's Bond Market Based on Major Capital Markets Overseas and Inter-bank Market Experience
}

\author{
Liu Xiaoti \\ Nanjing Universityof Aeronauticsand Astronautics, China, Jiangsu Province, Nanjing City, 211106 \\ China \\ Xiaoti08@163.com
}

Keywords: Bond market, Exchange, Inter-bank

\begin{abstract}
International Bond Market become a part of today's global financial markets which cannot be ignored after the rapid development of the wave of financial securities and IT reform. China's capital markets, especially the bond market, has already had a relatively complete market system, but compared with the mature markets of developed countries in terms of market size, market structure and regulatory system, there are still significant gaps. Through the research and development process of the United States, Europe, Canada and other major international bond market, this paper summarizes the experience of bond market for our learning and planning strategic objectives and future development path.
\end{abstract}

\section{Introduction}

After bond market experienced the wave of financial securitization and IT reform, the group has become a part of the global stock market which cannot be ignored. As we all know, the bond market can effectively allocate financial resources to reduce risk concentration in the banking system and strengthen market discipline. In Europe, Japan and other developed countries, the size of the bond market is much larger than the stock market. In China, compared with the mature markets of developed countries in terms of market size, market structure and regulatory system, there are still significant gaps. For example, the stock of bonds accounting for the proportion of GDP is much lower than the US and Japan.

In contrast, in recent years, our bond market distance is gradually reduced compared with the developed markets of Germany and France. China's total various types of bonds in annual inter-bank bond market are 40.43 trillion yuan in 2013 and 38.91 trillion yuan in 2014, and the total turnover of all types of bonds in exchange bond market are 1.01 trillion yuan and 1.41 trillion yuan, respectively. Through the research and development process of the United States, Europe, Canada and other major international bond market, this paper summarizes the experience of bond market for our learning and planning strategic objectives and future development path.

\section{Development experience in major bond market overseas}

Development experience in US bond market.(1)Perfect bond trading infrastructure and take platform advantage of fixed income.

The US bond secondary market is divided into two levels, inter-dealer market (also known as wholesale, B2B) and the market between customers and traders (also known as the counter market, B2C). Over the counter market, traders buy and sell quotations and liquidity to clients. Over the wholesale market, traders sell acquired positions in the retail market and manage positions risk. Counter market is the main source of profits for dealers, and effectively provides market liquidity. Wholesale is responsible for regulating the supply of all places, which has played a role in risk management. Now, China's fixed-income trading platform exchange agreement exists complex procedures, poor settlement efficiency and other issues, making the lack of counter market, thus traders lack motivation in the secondary market transactions, and inter-dealer wholesale market has also become a source without water, affecting the development of the entire fixed income platform. China should vigorously develop counter transactions, thus contributing to the direct docking 
between broker and the customer, exploring new profit growth point, in order to better develop all kinds of financial products, to better meet the needs of the customer's cash management.

(2)Actively carry out bond product innovation and attract market participants. i :Equity joins bond. US bond market is basically along the basic path of "interest rate products - credit products equity joins” product, which has a certain reference for China. Considering the size of the stock, due to the huge size of China's stock market, the bond market is relatively mature. Through equity-linked product to bound the bond market and the stock market, which is conducive to the expansion of the bond market and faster promoting development of the bond market.

ii : Structured products. American structured products develop rapidly, although structured products has been criticized in the sub-prime crisis, some clearly structured products still maintain a rapid growth, such as mortgage-backed securities (MBS) and exchange traded notes, and some are more suitable for exchange bond market. Currently, asset-backed debt securities in domestic market have a huge demand and broad space for development. First, the credit risk is lower. Second, the rate of return is high. Third, the bond asset-backed securities have relatively short deadline. Fourth, asset-backed securities have good liquidity.

iii: Derivative Products. In recent years, the development of related derivatives in US bond market has been significantly faster than the coil. Domestic launch of derivatives is a big trend, but it also faces many challenges. First, considering the policy limits, it is difficult to launch outside standard options or futures and it must design products within the existing framework of policy constraints. Second, looking for the underlying assets with high liquidity and market pricing to prevent the risk of market manipulation.

Development experience in Eurobond market. (1)Continue to promote the integration of resources in bond market. EU capital market has been far behind the US. The main reason is that the terms of the regional market segmentation is obvious. Issuance securities' trading, clearing, settlement, investors access, regulatory and other aspects are highly fragmented and market liquidity is low, and transaction costs are high, so market dominance is far better than the United States. From 1999, the EU has begun to eliminate market segmentation, reduce transaction costs in order to promote the reform and reorganization of market integration and enhance their competitiveness. EU capital markets' next plan focuses on promoting the harmonization of trading systems in various countries with respect to settlement entry system, hosted unified registration system, market supervision and operation rules. However, as the regional market, the situation of European bond issuers' highly fragment will persist in the long run. The existence of this situation will also lead to that the bond issue size is small, the big difference of credit and low release frequency, poor mutual substitution and low liquidity. In addition, the EU also has lowered the ratings of some member states in a few months.

(2)Perfect offer incentives to promote the construction of primary dealer system. Eurobond market maker has strong driven quote and prominent role. Almost all B2B electronic platforms in European bond markets have introduced a competitive market maker or liquidity provider. In addition to enjoying the powers of the primary market, the market makers also enjoy secondary market pricing, benefits and transaction costs compensation and equity arrangements, which greatly enhances the market maker's enthusiasm.

Primary trader is the success guarantee of debt issuance at the lowest cost, an integral part of open market counterparties of the central bank, an important secondary market liquidity providers and link between government primary bond and secondary bond market. European countries attach great importance to primary dealer, and strongly protect their related interests.

(3)Establish and improve the layered team qualified investors, separate trading, clearing and settlement functions. According to the net assets or other anti-risk indicators, the classification for qualified investors in bond market is a development trend. Different qualified investors participate in various bond trading products. European bond markets separate investors with fixed income platform and clearing participant. European bond type is very complicated, which requires a higher specialization. EU financial supervisory authorities classified investors. 
European bond markets have characteristics of trading, clearing, settlement and high degree of separation between registration and hosting, the dispersed and concentrated bond trading and clearing and settlement system reflect that the integration effect of the European bond market is obvious. Available revelation from European bond markets is that the focus is the transaction efficiency, fairness and investor protection, and clearing and settlement focuses on risk prevention. The manner of the transaction is the focus of attention in the Stock Exchange, and clearing and Settlement Company should focus on two elements of products and people and make reasonable arrangements for clearing and settlement patterns for risk prevention.

Development experience in Canadian bond market. (1)Strengthen the supervision of the use of debt financing.Legal basis for the implementation of debt management for Canada Government is "Financial Administration Act", which requires the government should submit Congress' annual government debt management strategy before the start of each fiscal year, and the strategy should be approved by Congress before implementation to the public. At the end of each fiscal year, the government must submit the "Annual Debt Management Report" to the Congress and publish it to the society, summarizing the work of the annual debt management. In addition, "the Bank of Canada Act" gives the government the right to exercise the Bank of Canada's financial agency to assist the financial sector in the management of government debt. Ministry of Finance and the Bank of Canada are jointly responsible for the management of government debt. The Government has set up a "fund management committee" to ensure compliance with security issuers and financial operations behavior. At the same time, it set up a "risk committee" which is responsible for monitoring and reporting risks in financial markets and assets. Canada also set up "Investment and Savings Agency" under the Ministry of Finance which is responsible for the daily management of retail bonds.

During the financial crisis, the Government of Canada succeeded in stabilizing domestic economic growth through massive fund-raising. From a longer time period, during the 1998-2008, in order to maintain the liquidity of government bonds in the secondary market, the Government of Canada maintains a sufficient amount of treasury bonds each year, but the net has not been a corresponding increase in government debt, and shows gradual downward trend. Thus, the more critical question in government debt risk control is how to finance "Using off" of debt.

(2)Attach great importance to the secondary market liquidity. Secondary market liquidity is an important measure degree of a country's level of bond markets in development and perfection. The Canadian government has always attached great importance to the issue of market liquidity. Higher market liquidity will remain as a debt management to develop and implement policies and measures. Fundamental objective of the Government of Canada debt management is "long-term stability and low-cost financing from the market”, the derived goal to ensure the achievement of fundamental objective is to establish and maintain a strong liquidity and improve the function of the secondary market. Though Canadian government bonds in the secondary market are modest, with high liquidity, so it will reduce market risk and ensure the successful completion of the government financing task each year.

(3)Further strengthen the cooperation between various government departments. Through the legal form, Canada makes a clear responsibilities division in various government departments in the bond market. Using a system to protect the coordination between various departments is a prerequisite for the government to implement effective management. The division of Ministry of Finance and the Bank of Canada is clear in treasury management, with more understanding, each special committee of an inter-departmental working monitors and assesses the implementation of the various departments to effectively protect the government's annual funding task complement successfully and healthy and stable development of the bond market. One of the major reasons for Canadian financial industry's less affected by the crisis is that the Canadian government bond market focused on the regulation of the financial industry very much.

(4)Give full play to the role of industry organizations in the market. At the same time of emphasizing the Government's management, the Canadian stock market also attaches great importance to industry self-management. The Canadian experience suggests that the establishment 
of multi-level marketing management system is conducive to the development of the market, government management and industry self-regulation should try both. Current industry organization for Canadian stock market is "Canadian investment industry self-management organization". As an industry organization, it undertakes a series of market management functions under the authority of the government departments.

\section{Development proposals in China's bond market}

Nurture and build a multi-level team of qualified investors. In current exchange bond market, the scale of institutional investors devoted to the bond investment is small, and compared with the bond markets of developed countries, there is a serious homogenization for self-investment accounts for the majority of the main institutions, brokers and speculative funds and other institutional investors in the strong colors of the market is not mainstream, the overall size is too small. Therefore, we should nurture more institutional investors to build diversified bondholders structure to support more institutional investors to carry out spot bonds and repo transactions in the exchange market, extend from the bond spot to repurchase bonds and other bonds, allowing banking institutions to be involved in fixed-income trading platform inquiry in order to achieve the expansion of its market size, and the promotion of an active market for the purpose of arbitrage trading and other speculative transactions.

Rich market varieties in exchange bond. In recent years, the product innovation in major bond markets overseas as well as the inter-bank bond markets is faster. Especially in the inter-bank bond markets, the project benefits bill, RMB bonds, asset-backed notes and other innovative products have been available. On the exchange bond markets, the following aspects should be done.

(1) Accelerate the "corporate bonds Pilot Measures" revision, to further expand the scope of issuers, simplify the review process of public offerings, establish a sound mechanism for non-public offering and promote the construction of multi-level bond market.

(2) Actively nurture private debt market, comprehensively establish and improve related systems in private debt. Currently, private placement bonds for SMEs have obtained considerable development and market acceptance, and it should timely expand private debt issuers and establish complete private bond transaction markets.

(3) Propose repurchase agreements as soon as possible, and promote foreign companies to issue foreign bonds and RMB bonds in exchange. Absorbing foreign experience and lessons of the financial crisis, drawing on relevant experience in the inter-bank market, developing exchange interest rate derivatives, conducting exchange cash bond forwards, interest rate swaps, interest rate futures and options, credit default swaps feasibility study.

Introduce market-maker system. In the major bond markets overseas, the market maker system is a basic system in price fluctuations stability of stock market and transaction efficiency improvement. Through an intermediary role of market makers, OTC bond trading can be achieved quickly and smoothly to maintain the trading volume and market liquidity of the bond itself. But the market makers institution is still a prototype, and its role has not yet played out. In addition, market maker rights and obligations have no complete or clear boundaries. Market maker quotes based on bilateral market and its demand have fluctuations and lack consistency. Corporate bonds have been listed on the traditional varieties in exchange, and still have some advantages in terms of trading volume and hosting capacity compared with the inter-bank markets. We should launch a true market maker system based on corporate bond products, with appropriate relief support, which is in favor of the consolidation of exchanges share, under the conditions of the regulatory system to rationalize the rapid development of the corporate bond market. When the exchange launches market-maker system, it should be careful not to become a byproduct of block trading platform, but should transform the real trading system. 


\section{References}

[1] Shao L. A Comparative Study of China's inter-bank bond market and the exchange bond market. Xiamen: Xiamen University, 2006.

[2] Zhang Y., Liu X. Discussion on the development of China's bond market. Management \& Technology, 2009(11): 136-137.

[3] Liu C., Wang F., Shi K., et al. Robust Hळ Control for Satellite Attitude Control System with Uncertainties and Additive Perturbation. International Journal of Science, 2014, 1(2): 1-9.

[4] Huang H., Zhu N. The Chinese Bond Market: Historical Lessons, Present Challenges, and Future Perspectives.China’s Emerging Financial Markets. Springer US, 2009: 523-546.

[5] Eichengreen B, Luengnaruemitchai P. Why doesn't Asia have bigger bond markets?. National Bureau of Economic Research, 2004.

[6] Green S P, He M. China's stock market: out of the valley in 2004?. The Royal Institute of International Affairs Briefing Paper, 2004 (1). 